\title{
Quasi-decadal variability in paleoclimate records: Sunspot cycles or intrinsic oscillations?
}

\author{
G. Garric ${ }^{1}$ and M. Huber ${ }^{2}$ \\ Danish Center of Earth System and Sciences, Niels Bohr Institute for Astronomy, Physics and Geophysics, University of \\ Copenhagen, Copenhagen, Denmark
}

Received 28 November 2002; revised 25 April 2003; accepted 16 May 2003; published 14 August 2003.

[1] Paleoclimatic proxies for interannual variability reveal power within the 7-15 year quasi-decadal (QD) band in Earth's history. Despite the fact that the best-established sources of QD variability in modern climate are internal, this QD variability in paleoclimatic records is commonly attributed to the $~ 11$ year "sunspot cycle" of solar variability. Intrinsic QD variability has received little attention in paleoclimatology. We apply two different modeling frameworks to assess the degree to which QD variability might have occurred in the past and question whether existing paleoclimate records, no matter how well-resolved, distinguish between internally driven and solar-driven variability. We show that even a simple atmospheric general circulation model (GCM), driven by constant solar radiation, produces climate oscillations with a period of $\sim 11$ years. Then, motivated by numerous studies arguing for the presence of sunspot cycles in Eocene $(\sim 50 \mathrm{Ma})$ paleoclimate records, we demonstrate that a fully coupled GCM simulation with constant solar forcing reproduces the full spectrum of reconstructed Eocene variability. In the examples we consider, there is no compelling reason to invoke solar cycles as a cause of interpreted variability. We stress the importance of identifying internal modes of variability from paleoclimate records to increase understanding of the climate system. INDEX TERMS: 3344 Meteorology and Atmospheric Dynamics: Paleoclimatology; 1620 Global Change: Climate dynamics (3309); 1650 Global Change: Solar variability; 3339 Meteorology and Atmospheric Dynamics: Ocean/atmosphere interactions (0312, 4504); KEYWORDS: paleoclimatology, climate variability, sunspot cycles, ocean/atmosphere variability, decadal cycles

Citation: Garric, G., and M. Huber, Quasi-decadal variability in paleoclimate records: Sunspot cycles or intrinsic oscillations?, Paleoceanography, 18(3), 1068, doi:10.1029/2002PA000869, 2003.

\section{Introduction}

\subsection{Motivation}

[2] Paleoclimatology can answer critical questions about climate and climate change. Most critically: What is the "natural," unforced variability of the climate system? What are the responses of the system to known, external forcing? Quasi-decadal (QD) variability, through its role in climate and in the detection of climate change, is currently the focus of much debate [Cane et al., 1997; Gu and Philander, 1997; Goody et al., 1998; Meehl et al., 2001]. Part of the controversy arises from the fact that recognition of QD climate variability requires time series that are long relative to the majority of modern "observational" records [e.g., Ghil and Vautard, 1991; Wunsch, 1999]. Interannual variability records generated from, e.g., tree ring time series, coral isotopic variations or varved sediments, can directly supplement such observational records where they are continuous and overlap [Evans et al., 2000; Urban et al., 2000; Mann et al., 2000; Cole et al., 2002] or they can provide windows into the operation of the climate system in

\footnotetext{
${ }^{1}$ Now at CERFACS/MERCATOR-OCEAN, Ramonville St. Agne, France.

${ }^{2}$ Now at Earth and Atmospheric Sciences, Purdue University, West Lafayette, Indiana, USA.
}

Copyright 2003 by the American Geophysical Union. 0883-8305/03/2002PA000869\$12.00 the deep past when the records are "floating" in time [Ripepe et al., 1991; Milana and Lopez, 1998]. Consequently, proxyderived records for interannual variability can play a pivotal role in identifying the stability of leading modes of variability and are also critical for constraining the relationship between global climate change and the spatial-temporal structure of these modes [Urban et al., 2000; Mann et al., 2000; Clement et al., 2000; Molnar and Cane, 2002].

[3] Within the QD band lies the 11 year solar (sunspot) cycle, which may be an important external climate forcing. As summarized below, many paleoclimate studies of interannual variability assume that past variability near this period must be solar cycle-driven. To our knowledge, there have been no modeling studies of QD variability, and no data studies focusing on the role of intrinsic oscillations, in the pre-Quaternary. By potentially misattributing internal QD variability in the paleoclimatic record to external forcing, unique opportunities to study the climate system are missed. Our aim is to test the robustness of internal QD variability to boundary condition changes representative of those found in Earth's past and to determine whether existing records distinguish between intrinsic and solarinduced variability. In the process we provide an example of how such records can verify the predictions of climate model simulations.

[4] First, we summarize past work on QD (section 1.2) and solar-driven (section 1.3) variability in the modern record and in the "deep" paleorecord (section 1.4). The 
close link between observed decadal variability and selfgenerated climate feedbacks in the present day suggests that internal QD variability was equally important in the past. In the succeeding section we test this hypothesis with numerical models with constant solar forcing. For this purpose we use two different types of GCM: the Simplified GCM (SGCM hereafter) integrated with fixed SSTs (section 2.1) and a state-of-the-art fully coupled GCM adapted to simulate Eocene climate $(\simeq 50 \mathrm{Ma})$ (section 2.2$)$. In these experiments we use the MultiTaper Method-Singular Value Decomposition (MTM-SVD) statistical approach to analyze low-frequency variability. This is a multivariate frequencydomain decomposition technique recently developed by Mann and Park [1999] that seeks to isolate statistically significant narrowband oscillations that are correlated among a large number of independent time series. This method has been successfully applied to observed data [Mann and Park, 1996; Venegas and Mysak, 2000; Tourre et al., 2001].

\subsection{Quasi-Decadal Periodicities in Modern Climate}

[5] Time series analysis and dynamical modeling studies have identified patterns and processes of climate variability on QD timescales. Global and regional time series analysis using spectral methods have identified power in the 715 year bands [Ghil and Vautard, 1991; Allen and Smith, 1996; Mann and Lees, 1996; Moron et al., 1998; Allan, 2000]. As reviewed by Marshall et al. [2001], in the North Atlantic, such variability is found in surface climate, sea ice concentrations, and the thermohaline circulation, and has frequently been linked to the North Atlantic Oscillation [Hurrell, 1995] and Arctic Oscillation [Thompson and Wallace, 1998]. Significant power has been found at 912 year [Venegas and Mysak, 2000], 10-11 year periods [Mann and Park, 1996] and longer (10-30 years [Marshall et al. [2001]). In the Pacific, other patterns express themselves as QD oscillations. These include the Pacific Decadal Oscillation (PDO) [Mantua and Hare, 2002], the Pacific North America pattern, and decadal-scale modulation of ENSO (the El Nino Southern Oscillation phenomenon [ $G u$ and Philander, 1997]). For example, Tourre et al. [2001] have identified and separated two patterns of coherent decadal and interdecadal climate signals in the Pacific Basin during the 20th Century. The decadal band peaks within the 10.8 to 11.9 year periods and resembles the pattern that Allan [2000] has identified in a 11-13 year band of variability aligning (spatially and temporally) with prolonged El Nino and La Nina events. These oscillations and their global effects have been confirmed by proxy records [Evans et al., 2000; Urban et al., 2000; Cole et al., 2002].

[6] A variety of numerical models ranging from box models [Quon and Ghil, 1995] to coupled general circulation models [e.g., Delworth et al., 1993; Latif and Barnett, 1994; Goodman and Marshall, 1999] generate lowfrequency variability, including in the QD band, without any varying solar forcing. Owing to their large heat capacity, the oceans play a key role in determining the period of decadal climate variability with two distinct contributors: the thermohaline and the wind-driven circulation. The thermohaline circulation, which involves long timescales, is a rich source for low-frequency variations and numerous simulations of deep oceanic circulation have suggested this as a potential driver of decadal variability [Weaver and Sarachik, 1991; Weaver et al., 1993; Winton and Sarachik, 1993; Chen and Ghil, 1995; Yang and Neelin, 1997]. Gu and Philander [1997] have suggested an alternative mechanism that relies on modulation of ENSO via the delays associated with midlatitude-tropical ocean advection timescales. Other proposed mechanisms explain fluctuations on decadal timescales by invoking the winddriven circulation and stochastic resonance [Hasselmann, 1976; Sura et al., 2000]. The hypothesis being that much of observed climate variability can be explained as the integral response of the oceans to stochastic (day-to-day) atmospheric variability [Battisti et al., 1995; Griffies and Tziperman, 1995].

[7] In addition to the large body of evidence of the ability of the ocean-only and the coupled system to oscillate at QD timescales, the atmosphere has provided some surprises. In clear contradiction to the usual assertion, based on linear scaling arguments, that the atmosphere has no memory longer than about one month, studies by James and James [1989], and more recently, by Garric et al. [2003], have found a significant presence of decadal variability in an atmospheric GCM forced by fixed surface boundary conditions.

\subsection{Modern Solar Cycle-Driven Periodicities}

[8] The response of the climate system to external parameter changes, such as in the amount of incoming solar radiation (insolation), is another crucial factor in need of constraint. Consequently, interest has focused on the relationship between solar variability and observed oscillations and trends in Earth's present climate (see the proceedings of a recent workshop entitled "Solar variability and climate" [Friis-Christensen et al., 2000]. Labitzke and Van Loon [1989] and Van Loon and Labitzke [2000] have found clear evidence of climate changes in the lower stratosphere and troposphere in phase with insolation variation. A modulation of SSTs of about $0.1 \mathrm{~K}$ in phase with the 11 year solar cycle was inferred by White et al. [1997].

[9] Livingstone and Hajdas [2001] list work done by R. G. Currie on the solar cycles detected in many time series, ranging from modern instrumental data on air temperature, air pressure, precipitation and sea level to data on the Earth's rotation and the length of the day, ${ }^{10} \mathrm{Be}$ concentrations in Greenland ice cores, tree ring thicknesses, floods, earthquake frequencies, agricultural and livestock production, wine harvests and fish catches, and even military engagements.

[10] However, apart from the study of White et al. [1997], very few global surface records show a clear 11 year variation in phase with solar activity variations. Moreover, such studies do not generally show correlations with strong statistical confidence. Thejll [2001] has shown for example that the decadal signal is statistically significant for individual stations, but it was not possible to show that the signal is statistically significant globally. Most records of 11 year solar variability reflect changes in the upper 
atmosphere, which are also more likely to be directly caused by relatively small changes in insolation

[11] Furthermore, the proposed physical mechanisms behind these correlations are still speculative. Dickinson [1975] suggested that cosmic ray fluxes are anticorrelated with the sunspot cycle and that cosmic ray ionization could increase the concentration of cloud condensation nuclei, leading to a relationship between solar activity and cloudiness. Mohnen [1990] criticized this possibility. Recently, Svensmark and Friis-Christensen [1997] claimed to have discovered a significant relationship between cloud cover on a global scale and the cosmic ray flux over the solar cycle. This claim has been criticized, in turn, by Kernthaler et al. [1999], based on a careful analysis of the occurrence of different types of clouds in the International Satellite Cloud Climatology Project (ISCCP) data base.

[12] While plagued by their own subtleties, one means to test Sun-climate relationships is to use ocean-atmosphere GCMs to simulate the effect on climate of a change in solar irradiance. Using such a model, Haigh [1996] changed insolation and stratospheric ozone to investigate the response of the atmosphere to the solar cycle, finding effects similar to, although generally smaller in magnitude than, those observed in nature. A simulation in which only solar irradiance was changed showed a much weaker response. Cubasch and Voss [2000] used as input two different reconstructed time series of total solar irradiance, and find that the global average temperature response to the 11 year insolation variation is heavily damped, presumably by the ocean's large thermal inertia. Haarsma et al. [2000] assessed the response of a coupled model to an estimate of the solar variability since 1700 and to a series of idealized sinusoidal solar forcings. On the regional scale, the internal variability dominates the solar-induced variability. And, for a variation in insolation with amplitude $0.5 \mathrm{Wm}^{-2}$ and a period of 11 years, the response is indistinguishable from background intrinsic variability.

[13] Thus, as Rind [2002, 673] suggests, "each solar forcing mechanism operating on timescales from billions of years to decades fails to generate the expected climate response in important respects, although some relations are found." As a result of such issues, the possible connection between solar variability and global climate change remains controversial. In general, there is enough evidence to suggest the plausibility but not the necessity of a significant role for solar insolation cycles as drivers of QD climate variability.

\subsection{Paleoclimate Records of "Sunspot" Cycles?}

[14] Despite these uncertainties, QD cycles in climate proxies are routinely linked to hypothesized sunspot cycles in the paleoclimate literature, which has led to the "lumping" of peaks between 8 and 15 years into 11 years. We have selected a few examples. Damnati and Taieb [1995] found peaks in the 8-14 yrs interval in laminated deposits in Kenya during the Pleistocene/Holocene transition and suggested that this multiannual climatic variation "could be related to the" sunspot cycle. Kurths et al. [1993, 359] found evidence for a main period of $\sim 12.5$ years in a tree ring record of Miocene (about 15-20 million years ago). They conclude "this is near the present basic solar activity period of approx. 11 years". Some of the best examples of interannual variability occur in the Green River formation, as described by Ripepe et al. [1991, 1162]. They find periodicities of $4-5,8,10,14$, and 15 years; the latter three they group into one peak of 12.6 years. From this, they conclude that this periodicity, "is presumably the 11 year cycle of Bradley [1929] and the 10.4 year cycle of Crowley et al. [1986]. We too attribute it to the sunspot cycle." As a further extension of interpretation of all variability as being induced by sunspot cycles, Mingram [1998] made a link between 5.5 year cycles found in laminated Eocene maar lake sediments and the sunspot cycle, by speculating some unknown harmonic phenomenon. As cited therein [e.g., Ernesto and Pacca, 1981], related periods of 5.5 years have been similarly attributed to sunspots in the Permo-Carboniferous. In Carboniferous glaciomarine rhythmites in western Argentina, Milana and Lopez [1998] detected peaks at 12 and 9 years and interpreted them as probably of sunspot cycle origin.

\section{Model Experiments and Results}

\subsection{Quasi-Decadal Variability With the SGCM}

[15] Process models provide the test of hypotheses concerning causes of climate variability. We investigate the possibility of intrinsic atmospheric variability using the simplest model that captures the basic elements of atmospheric dynamics. This model is run without continents, and with zonally constant and fixed SSTS. In a sense, such a configuration represents one of the simplest modeling frameworks for studying climate in general, because it focuses on what all time intervals have in common $(2 / 3$ of Earth's surface is ocean) and ignores those aspects that we know change substantially on paleotimescales. The SGCM is a variant of the Hoskins and Simmons [1975] Reading multilayer spectral model, with a vertical resolution of 10 (sigma) levels and horizontal (spectral) resolution of 31 wave numbers (T31), or $\simeq 3.7^{\circ}$ grid spacing. A single hemisphere is assumed with symmetry about the equator. A Rayleigh friction term is applied at the lowest level and diabatic tendencies include a "Newtonian cooling" term, together with temperature tendencies due to boundary layer heat fluxes and dry convective adjustment. The Newtonian cooling term represents the effects of solar radiation, longwave cooling and deep convection in the tropics. The restoration temperature is chosen with slightly stable stratification and a constant temperature difference between the equator and the Pole of $50^{\circ} \mathrm{K}$, simulating constant Southern Hemisphere winter conditions with no seasonal cycle. Further details on the SGCM can be found in the work of James and Gray [1986], James and James [1989], and Garric et al. [2003]. Derived variants on this model have been widely used and are being coupled to ocean models (see http://puma.dkrz.de/planet).

[16] The SGCM was run for a total of 505 years. The first 5 years are discarded as a spin-up period, and spectral analysis is made over the last 500 years. Despite the model's simplicity, its zonal-mean climatology is surprisingly realistic as shown by Garric et al. [2003]. Patterns and magnitudes of poleward eddy fluxes of heat and momentum in the winter midlatitudes are similar to those observed. 


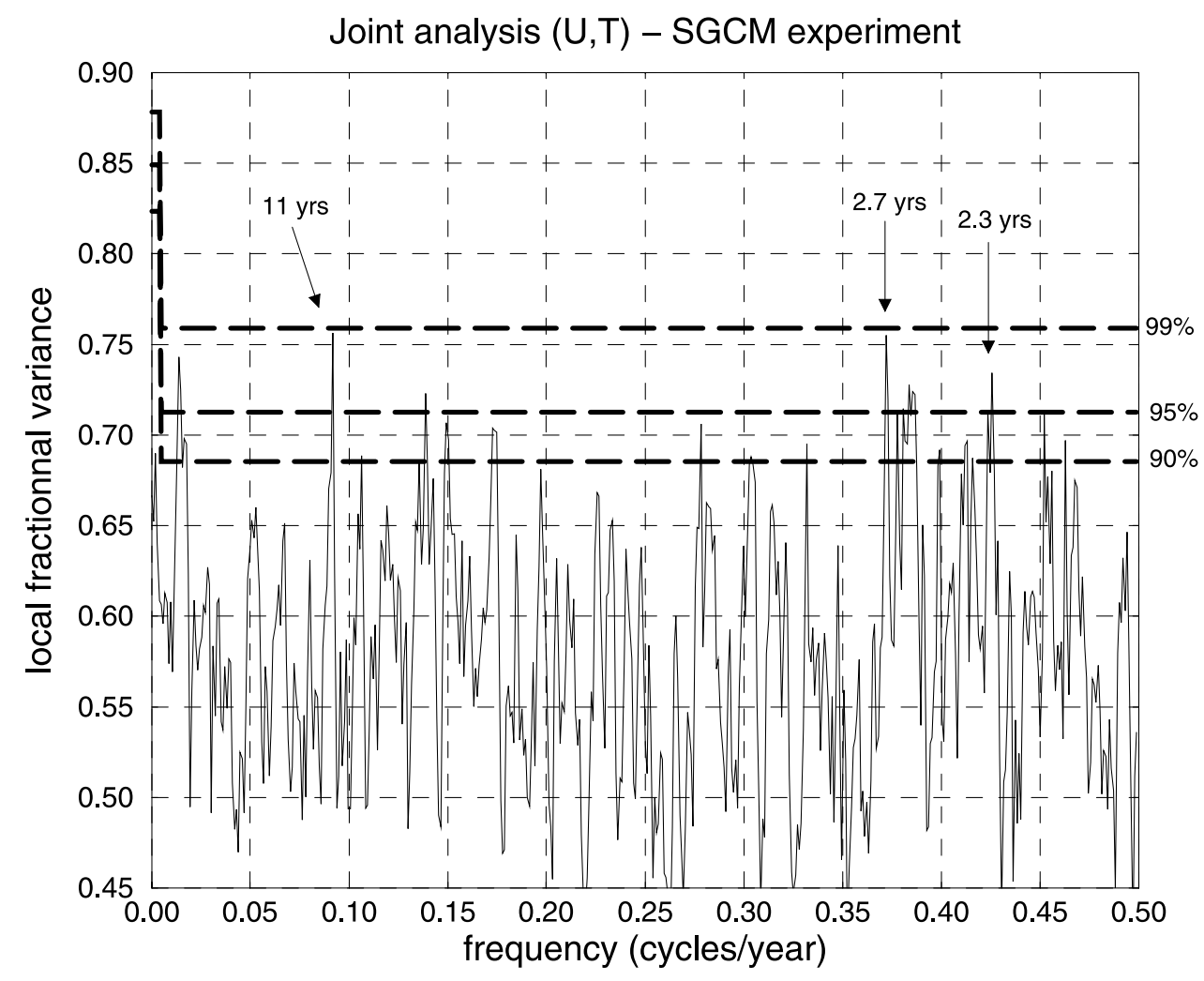

Figure 1. Local fractional variance (LFV) spectrum based on 500 years of the SGCM run for the joint zonal mean zonal wind and temperature fields. The $99 \%, 95 \%$, and $90 \%$ significance levels are obtained from bootstrap resampling.

[17] The local fractional variance (LFV) spectrum obtained from the application of the MTM-SVD method to the joint zonal mean of zonal wind and of temperature is shown in Figure 1. It reveals statistically significant $(\geq 95 \%$ level) coherent variability among the two variables on the following timescales: a QD signal with a sharp peak at $\sim 11$ years and a broad quasibiennial signal.

[18] The spatial reconstruction of the zonal wind and the temperature [see Garric et al., 2003] associated with the QD signal bears a close resemblance to the principal modes of the observed low-frequency variability of the wintertime zonal mean jets, the so-called "annular mode" [Thompson and Wallace, 2000]. Although the physical mechanisms behind this significant low-frequency variability in our "aqua-planet" simulation are still under investigation, James et al. [1994] suggested that the cumulative effects of multiple baroclinic life cycles could lead to the internal generation of this decadal signal. As described in the work of Garric et al. [2003], when a sea ice component is added to the model, significant variability is found at 3.2, 4, 5.7, 11 , and 25 years and the overall spectrum is "reddened." These results indicate that the basic quasi-biennial and QD variability are robust, but that the addition of other processes (in this case, sea ice interaction) lead to additional peaks.

\subsection{Eocene QD Variability in CCSM}

[19] As a second and less idealized exploration of QD variability, we analyze simulations of Eocene climate made with the fully coupled, ocean-atmosphere-land surface-sea ice GCM, the Community Climate System Model (CCSM) developed at NCAR [Blackmon et al., 2001]. We explore Eocene variability because we have performed one of only a handful of fully coupled GCM simulations of a "deep" paleoclimate and because the interannual variability of the Eocene is well characterized relative to many time intervals in Earth's past. CCSM version 1 is described and validated for modern conditions in the work of Boville and Gent [1998] and references therein, and the June, 1998 issue of Journal of Climate is devoted to it. Our results are produced with an updated version, 1.4, described in and used for modern, Eocene and Cretaceous experiments in the work of Otto-Bliesner and Brady [2001] and [Otto-Bliesner et al., 2002], and briefly below. The atmospheric and land models are the Community Climate Model 3.6.6 and the Land Surface Model 1.2 at T31 resolution, coupled to NCAR's Ocean Model 1.5 and the Community Sea Ice Model 2.2. The latter models are on a stretched grid with $0.9^{\circ}$ equatorial and $1.8^{\circ}$ high-latitude meridional grid spacing. The longitudinal grid spacing is $3.6^{\circ}$.

[20] The CCSM is one of the few coupled GCMs that does not require "flux corrections"; this allows our paleoclimate simulation to evolve freely without an arbitrary forcing toward a specified mean state. In the Eocene simulation, we incorporate realistic, "best guess" Eocene bathymetry, topography, land surface conditions, $p \mathrm{CO}_{2}$, and vegetation as boundary conditions (described in the work of 


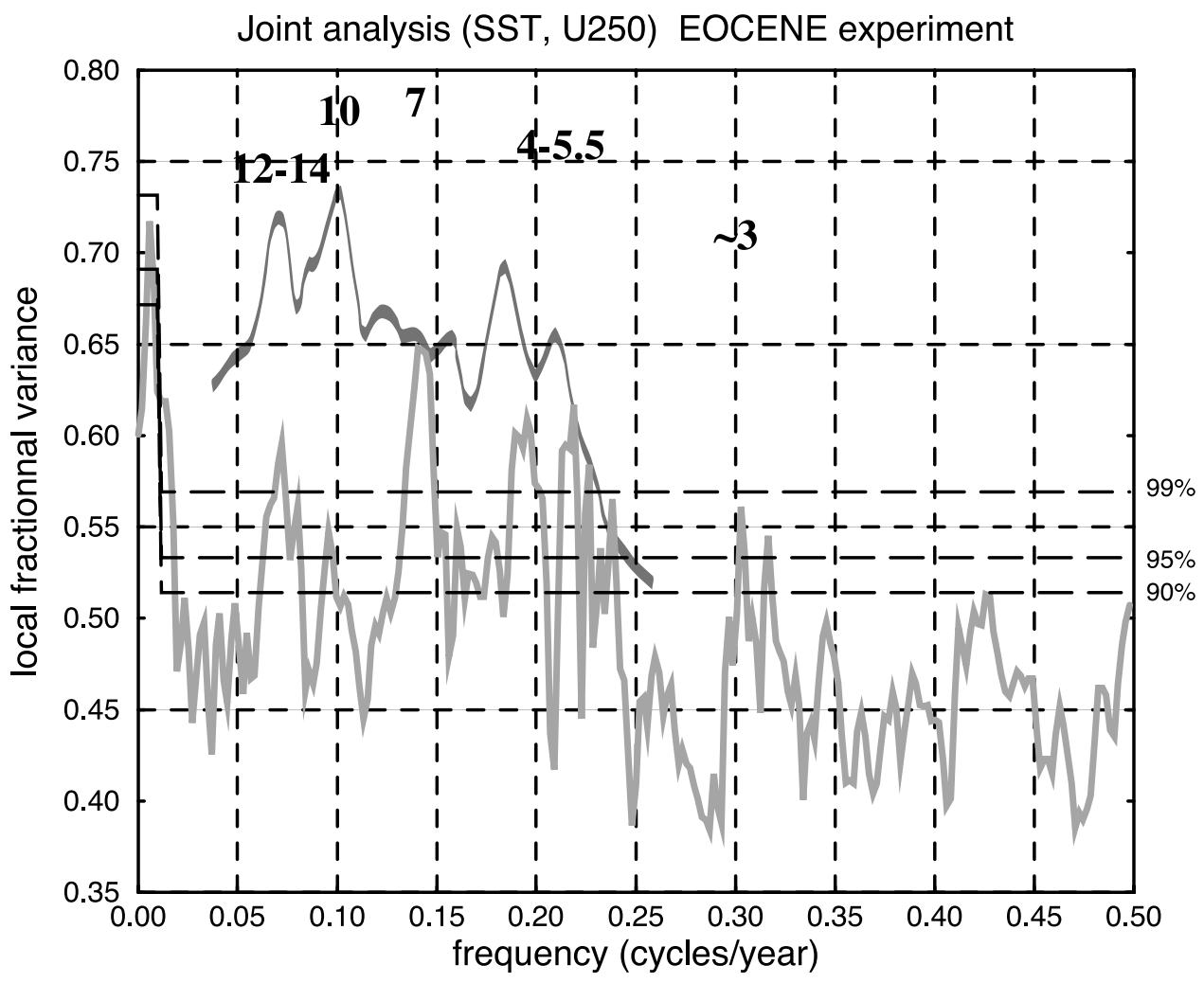

Figure 2. LFV spectrum of the joint zonal wind at $250 \mathrm{mb}$ and SST fields from Eocene CCSM simulation (blue). Significant peaks in the simulated spectra are indicated on figure. In green, is the stacked spectra from proto-Wyoming produced by Ripepe et al. [1991] reproduced here for comparison to the modeled spectra. Note that the confidence intervals apply only to the model LFV spectra (no estimates of statistical significance were made by Ripepe et al. [1991]). That spectra has been shifted up to make the detailed features more visible. See color version of this figure at back of this issue.

Huber et al. [2003]. Huber and Sloan [2001] described their methodology of getting the initial and boundary conditions of the Eocene and of accelerating the convergence of the deep ocean to a stable and a convergent Eocene case. The reader is referred to Huber et al. [2003] and Huber and Sloan [2001] for a detailed discussion of the predicted Eocene mean state. However, briefly, tropical and extratropical model-predicted zonal mean sea surface temperatures (SST) are warmer than modern values, by 3 and $7^{\circ} \mathrm{C}$, respectively, and deep ocean temperatures are warmer by $6-10^{\circ} \mathrm{C}$ highlighting the "greenhouse" state of Eocene climate. The simulation described here has been integrated for over 3,000 years in an accelerated iterative mode followed by over 300 years in synchronously coupled mode. The last 190 years are analyzed for variability.

[21] The local fractional variance (LFV) spectrum obtained from the application of the MTM-SVD method to the joint zonal wind at $250 \mathrm{mb}$ and SST during the 190 years of the CCSM Eocene run is shown in Figure 2. Interestingly, the spectra reveal a significant peak (at the $95 \%$ level) at 10.5 years, in agreement with the Eocene proxies (above). It also reveals statistically significant (at the $99 \%$ level) coherent variability among the two variables on the following timescales: a QD signal with a broad peak at $12-14$ years, a sharp peak around 7 years and a broad interannual signal in the 4-6 years band. The 4-6 years signal shows the presence of an El Niño-like phenomenon in the predicted Eocene tropical band [see Huber and Caballero, 2003].

[22] The spatial reconstruction of the SST anomalies at the significant 12.5 (nearly identical to the 10.5 year signal) years signal is shown in Figure 3. The pattern is very similar to those found in present-day modeling and data studies [cf. Allan, 2000]. While the details of the variability are complex, the main feature in the Pacific is an ENSO-like oscillation that works in much the way described by $G u$ and Philander [1997], where midlatitude advection anomalies propagate into the tropics generating a large response. This modern tendency to produce protracted El Niños on QD timescales is a cause of much uncertainty with regards to identifying a global warming signal in the Pacific [Cane et al., 1997]. The expression of QD variability in the wind fields bear the hallmarks of the "annular mode" (not shown). The fact that such patterns may have occurred in past "greenhouse" climates may have broad implications. In general the agreement between global coupled oscillations of important climate properties (large-scale winds and SSTS) and the proxy record at 4-6, 7-8, 10-11, and 1214 year periods compares favorably with those produced by models in the present day [Bell et al., 2003; Meehl et al., 2001] and is a verification of the skill of the simulation. 

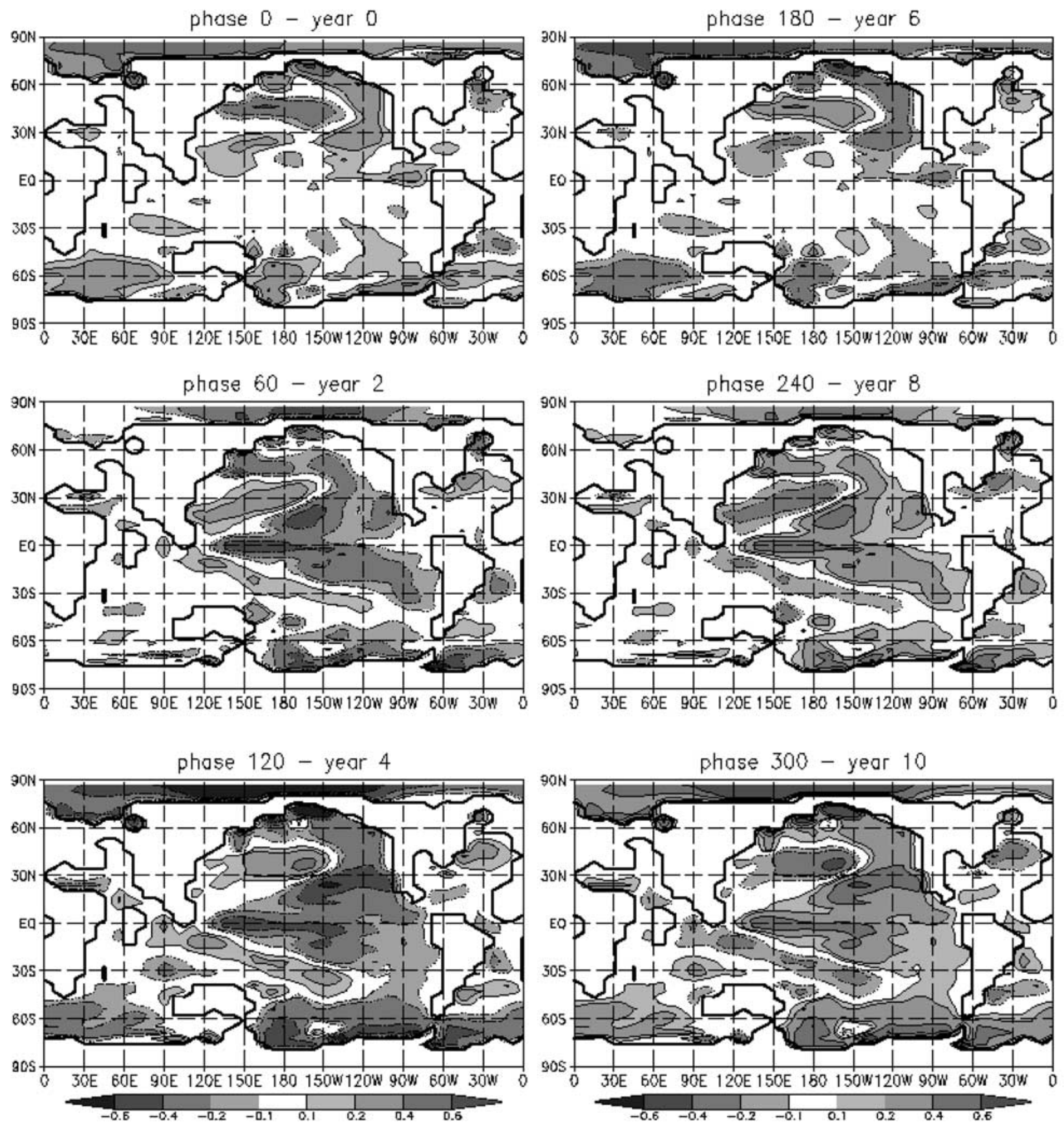

Figure 3. Spatial reconstruction of Eocene sea surface temperature anomalies (in ${ }^{\circ} \mathrm{C}$ ) during one complete QD cycle (12.5 years). The patterns are shown at 6 consecutive snapshots separated by approximately 2 years. See color version of this figure at back of this issue.

Alternatively, the general agreement between the model and data may be interpreted as an indication of the robustness of these modes, and not of the particular skill of the model.

\section{Discussion and Conclusions}

[23] Records of interannual variability are being continuously generated for many time intervals in Earth history. Rigorous identification of solar cycle-driven variability in a past climate requires that the reconstructed time series be significantly different than an appropriate "null model." This null model is reasonably assumed to be "red noise" under most circumstances, but, based on the existence of intrinsic variability that creates identifiable spectral peaks in this range under modern conditions, the null model must also include QD variability.

[24] We have provided an example of an oscillation at roughly 11 years that is internal to the atmosphere and exists 
under quite general circumstances, thus is likely to be pervasive throughout the paleoclimate record. Until exhaustive modeling studies of QD variability are performed for each time period in Earth history, or until the robustness of these modes to paleoconfigurations is theoretically disproved, there is no basis for ascribing variability in the 11 year range to factors other than intrinsic QD oscillations. These results indicate that any paleoclimate interpretation of solar cycle-driven variability that does not also contain independent proxies for insolation variability is unlikely to reach firm conclusions.

[25] This does not change the fact that a QD solar-induced cycle-climate link is plausible or even likely in the past. In reality, both forced and intrinsic modes probably coexist. Waple et al. [2002] have formulated an hypothesis in which the intrinsic QD variability can resonate with the 11 year solar cycle during periods of unusually high solar cycle amplitude but not during periods of lower amplitude solar variability during which the same mode may exhibit largely stochastically excited internal variability. This idea is also supported by White et al. [1998] who suggest that natural modes of Earth's variability are phase-locked to the solar irradiance cycle.
[26] Identification of these natural modes therefore is crucial to understanding these processes regardless of whether one believes the oscillations are actually driven externally or internally. If due attention is paid to the full panoply of variability in these records, usually including power around 2, 5, 8, 11, and 14 years, paleoclimatic proxies can provide a unique window into the patterns and processes of variability in Earth's past. An example of the utility of such analysis is provided by the verification of the modeled Eocene variability against Eocene lake records, with agreement at $\sim 5,8,11,13$ years (see Figure 3 ). The implication of that result is that the model is providing accurate predictions of variability, even in the deep past, and that ENSO, the "annular mode" and QD variability are robust features of climate, even under "greenhouse" conditions.

[27] Acknowledgments. The authors gratefully acknowledge the Danish National Research Foundation for supporting this research. The authors wish to thank Michael Mann for kindly providing the MTM-SVD routines and $\mathrm{S}$. Venegas for her assistance in handling them. The authors gratefully acknowledge support from DCESS and NSF ATM 9810799. We also thank the editor for his comment and Eric Steig and Gavin Schmidt for their reviews.

\section{References}

Allan, R. J., Enso and climatic variability in the past 150 years, in El Niño and the Southern Oscillation-Multiscale Variability and Global and Regional Impacts, edited by H. F. Diaz and V. Markgraf, pp. 3-56, Cambridge Univ. Press, New York, 2000

Allen, M. R., and L. A. Smith, Monte Carlo SSA: Detecting irregular oscillations in the presence of colored noise, J. Clim., 9(12), 3373-3404, 1996.

Battisti, D. S., U. S. Bhatt, and M. A. Alexander, A modeling study of the interannual variability in the wintertime North Atlantic Ocean, J. Clim., 8, 3067-3083, 1995.

Bell, J. L., L. C. Sloan, J. Revenaugh, and P. B. Duffy, Evaluation of Northern Hemisphere natural climate variability in multiple temperature reconstructions and global climate model simulations, Global Planet. Change, 37, 1932, 2003.

Blackmon, M., et al., Community Climate System Model, Bull. Am. Meteorol. Soc., 82(11), 2357-2376, 2001

Boville, B. A., and P. R. Gent, The NCAR Climate System Model version one, J. Clim., 11, $1115-1130,1998$

Bradley, W. H., The varves and climate of the Green River epoch, U.S. Geol. Surv. Prof. Pap. 158 , pp. 87-110, U.S. Geol. Surv., Reston, Va., 1929.

Cane, M. A., A. C. Clement, A. Kaplan, Y. Kushnir, D. Pozdnyakov, R. Seager, S. E. Zebiak, and R. Murtugudde, Twentieth-century sea surface temperature trends, Science, 275, 957-960, 1997.

Chen, F., and M. Ghil, Interdecadal variability of the thermohaline circulation and high-latitude surface fluxes, J. Phys. Oceanogr., 25, 25472568, 1995.

Clement, A. C., R. Seager, and M. A. Cane, Suppression of El Niño during the Mid-Holocene by changes in the Earth's orbit, Paleoceanography, 15(6), 731-737, 2000.

Cole, J. E., J. T. Overpeck, and E. R. Cook, Multiyear La Niña events and persistent drought in the contiguous United States, Geophys. Res Lett., 29(13), 251-254, 2002.

Crowley, K. D., C. E. Duchon, and J. Rhi, Climate records in varved sediments of the Eocene Green River Formation, J. Geophys Res., 91(D8), 8637-8647, 1986.

Cubasch, U., and R. Voss, The influence of total solar irradiance on climate, Space Sci. Rev., 94, 185-1989, 2000.

Damnati, B., and M. Taieb, Solar and ENSO signatures in laminated deposits from Lake Magadi (Kenya) during the Pleistocene/Holocene transition, J. Afr. Earth Sci., 21(3), 373382, 1995.

Delworth, T., S. Manabe, and R. Stouffer, Interdecadal variations of the thermohaline circulation in a coupled ocean-atmosphere model, J. Clim., 6, 1993-2011, 1993.

Dickinson, R. E., Solar variability and the lower atmosphere, Bull. Am. Meteorol. Soc., 56, 1240-1248, 1975 .

Ernesto, M., and I. G. Pacca, Spectral analysis of permocarboniferous geomagnetic variation data from glacial rhythmites, Geophys. J. R. Astron. Soc. 67, 641-647, 1981.

Evans, M. N., A. Kaplan, and M. A. Cane, Intercomparison of coral oxygen isotope data and historical sea surface temperature (SST): Potential for coral-based SST field reconstructions, Paleoceanography, 15(5), 551-563, 2000

Friis-Christensen, E., C. Fröhlich, J. D. Haigh, M. Schüssler, and R. VonSteiger (Eds.), Solar variability and climate-Proceedings of an ISSI workshop, Space Sci. Rev., 94, 427 pp., 2000 .

Garric, G., S. A. Venegas, C. E. Tansley, and I. N. James, Atmosphere-sea ice low frequency variability with a simple model of the Southern Hemisphere., Q. J. R. Meteorol. Soc., 129, 2347-2366, 2003

Ghil, M., and R. Vautard, Interdecadal oscillations and the warming trend in global temperature time series, Nature, 350, 324-327, 1991.
Goodman, J., and J. Marshall, A model of decadal middle-latitude atmosphere-ocean coupled mode, J. Clim., 12, 621-641, 1999.

Goody, R., J. Anderson, and G. North, Testing climate models: An approach, Bull. Am. Meteorol. Soc., 79(11), 2541-2549, 1998.

Griffies, S. M., and E. Tziperman, A linear thermohaline oscillator driven by stochastic atmospheric forcing, J. Clim., 8, 2440-2453, 1995.

Gu, D., and G. Philander, Interdecadal climate fluctuations that depend on exchanges between the tropics and extratropics, Science, 275, 805-807, 1997.

Haarsma, R. J., S. S. Drijfhout, J. D. Opsteegh, and F. M. Selten, The impact of solar forcing on the variability in a coupled climate model, Space Sci. Rev., 94, 287-294, 2000.

Haigh, J. D., The impact of solar variability on climate, Science, 272(5264), 981-984, 1996.

Hasselmann, K., Stochastic climate models. part I: Theory, Tellus, 28, 473-485, 1976.

Hoskins, B. J., and A. J. Simmons, A multi-layer spectral model and the semi-implicit method, Q. J. R. Meteorol. Soc., 101, 637-655, 1975.

Huber, M., and R. Caballero, Eocene El Niño: Evidence for robust tropical dynamics in the "hothouse", Science, 299, 877-881, 2003.

Huber, M., and L. C. Sloan, Heat transport, deep waters, and thermal gradients: Coupled simulation of an Eocene greenhouse climate, Geophys. Res. Lett., 28(18), 3481-3484, 2001.

Huber, M., L. Sloan, and C. Shellito, Early Paleogene oceans and climate: A fully coupled modelling approach using the NCAR CSM, in Causes and Consequences of Globally Warm Climates in the Early Paleogene, Geol. Soc. of Am. Spec. Pap., vol. 369, pp. 25-47, edited by S. L. Wing et al., Geol. Soc. of Am., Boulder, Colo., 2003.

Hurrell, J. W., Decadal trends in the North Atlantic Oscillation: Regional temperatures and precipitations, Science, 269(5224), 676-679, 1995

James, I. N., and L. J. Gray, Concerning the effect of surface drag on the circulation of a 
baroclinic planetary atmosphere, Q.J.R. Meteorol. Soc., 112, 1231-1250, 1986.

James, P. M., and I. N. James, Ultra-low-frequency variability in a simple atmospheric circulation model, Nature, 342, 53-55, 1989.

James, P. M., K. Fraedrich, and I. N. James, Wave-zonal flow interaction and ultra-low frequency variability in a simplified global circulation model, Q. J. R. Meteorol. Soc., 120, 1045-1067, 1994.

Kernthaler, S. C., R. Toumi, and J. D. Haigh, Some doubts concerning a link between cosmic-ray fluxes and global cloudiness, Geophys. Res. Lett., 26, 863-866, 1999.

Kurths, J., C. Spiering, W. Mullerstoll, and U. Striegler, Search for solar periodicities in Miocene tree-ring widths, Terra Nova, 5(4), $359-363,1993$

Labitzke, K., and H. Van Loon, Association between the 11-year cycle solar cycle, the QBO and the atmosphere. part I: The troposphere and stratosphere in the Northern Hemisphere in winter, J. Clim., 2(6), 554-565, 1989.

Latif, M., and T. P. Barnett, Causes of decadal climate variability over the North Pacific and North America, Science, 266, 634-637, 1994.

Livingstone, D. M., and I. Hajdas, Climatically relevant periodicities in the thicknesses of biogenic carbonate varves in Soppensee, Switzerland $(9740-6870$ calendar yr BP), J. Paleolimnol., 25, 17-24, 2001.

Mann, M. E., and J. M. Lees, Robust estimation of background noise and signal detection in climatic time series, Clim. Change, 33(3), 409-445, 1996.

Mann, M. E., and J. Park, Joint spatiotemporal modes of surface temperature and sea level pressure variability in the Northern Hemisphere during the last century, J. Clim., 9, 2137-2162, 1996

Mann, M. E., and J. Park, Oscillatory spatiotemporal signal detection in climate studies: A multiple-taper spectral domain approach, $A d v$. Geophys., 41, 1-131, 1999.

Mann, M. E., R. S. Bradley, and M. K. Hughes, Long-term variability in the El Niño/Southern Oscillation and associated teleconnections, in El Niño and the Southern Oscillation-Multiscale Variability and Global and Regional Impacts, edited by H. F. Diaz and V. Markgraf, pp. 357-412, Cambridge Univ. Press, New York, 2000.

Mantua, N. J., and S. R. Hare, The Pacific Decadal Oscillation, J. Oceanogr., 58(1), 35-44, 2002.

Marshall, J., et al., North Atlantic climate variability: Phenomena, impacts and mechanisms, Int. J. Climatol., 21, 1863-1898, 2001.

Meehl, G. A., R. Lukas, G. N. Kiladis, K. M. Weickmann, A. J. Matthews, and M. Wheeler, A conceptual framework for time and space scale interactions in the climate system, Clim. Dyn., 17, 753-775, 2001.
Milana, J. P., and S. Lopez, Solar cycles recorded in carboniferous glacimarine rhythmites (western Argentina): Relationships between climate and sedimentary environment, Palaeogeogr. Palaeoclimatol. Palaeoecol., 144(1-2), 3763, 1998.

Mingram, J., Laminated Eocene Maar-Lake sediments from Eckfeld (Eifel region, Germany) and their short-term periodicities, Palaeogeogr. Palaeoclimatol. Palaeoecol., 140, 289-305, 1998.

Mohnen, V. A., Stratospheric ion and aerosol chemistry and possible links with cirrus cloud microphysics-A critical assessment, J. Atmos. Sci., 47, 1933-1948, 1990.

Molnar, P., and M. A. Cane, El Nio's tropical climate and teleconnections as a blueprint for pre-Ice Age climates, Paleoceanography, 17(2), 1021, doi:10.1029/2001PA000663, 2002 .

Moron, V., R. Vautard, and M. Ghil, Trends, interdecadal and interannual oscillations in global sea-surface temperatures, Clim. Dyn., 14, 545-569, 1998.

Otto-Bliesner, B. L., and E. C. Brady, Tropical Pacific variability in the NCAR Climate System Model, J. Clim., 14(17), 3587-3607, 2001.

Otto-Bliesner, B. L., E. C. Brady, and C. Shields, Late Cretaceous ocean: Coupled simulations with the National Center for Atmospheric Research Climate System Model, J. Geophys. Res., 107(D2), doi:10.1029/2001JD000821, 2002.

Quon, C., and M. Ghil, Multiple equilibria and stable oscillations in thermosolutal convection at small aspect ratio, J. Fluid Mech., 291, 33 56,1995

Rind, D., The Sun's role in climate variations, Science, 296, 673-677, 2002.

Ripepe, M., L. T. Roberts, and A. G. Fischer, ENSO and sunspot cycles in varved Eocene oil shales from image analysis, J. Sediment. Petrol., 61(7), 1155-1163, 1991.

Sura, P., F. Lunkeit, and K. Fraedrich, Decadal variability in a simplified wind-driven ocean model, J. Phys. Oceanogr., 30, 1917-1930, 2000.

Svensmark, H., and E. Friis-Christensen, Variation of cosmic-ray flux and global cloud coverage-A missing link in solar-climate relationships, J. Atmos. Sol. Terr. Phy., 59(11), 1225-1232, 1997.

Thejll, P. A., Decadal power in land air temperatures: Is it statistically significant?, J. Geophys. Res., 106(D23), 31,693-31,702, 2001.

Thompson, D. W. J., and J. M. Wallace, The Arctic Oscillation signature in the wintertime geopotential height and temperature fields, Geophys. Res. Lett., 25, 1297-1300, 1998.

Thompson, D. W. J., and J. M. Wallace, Annular modes in the extratropical circulation. part I, Month-to-month variability, J. Clim., 13, 1000-1016, 2000.
Tourre, Y. M., B. Rajagopalan, Y. Kushnir, M. Barlow, and W. B. White, Patterns of coherent decadal and interdecadal climate signals in the Pacific basin during the 20th century, Geophys. Res. Lett., 28(10), $2069-$ 2072, 2001.

Urban, F. E., J. E. Cole, and J. T. Overpeck, Influence of mean climate change on climate variability from a 155 -year tropical pacific coral record, Nature, 407, 989-993, 2000.

Van Loon, H., and K. Labitzke, The influence of the 11-year solar cycle on the stratosphere below 30km: A review, Space Sci. Rev., 94 $259-278,2000$

Venegas, S. A., and L. A. Mysak, Is there a dominant timescale of natural climate variability in the Arctic?, J. Clim., 13, 3412-3434, 2000

Waple, A. M., M. E. Mann, and R. S. Bradley, Long-term patterns of solar irradiance forcing in model experiments and proxy based surface temperature reconstructions, Clim. Dyn., 18 , $563-578,2002$

Weaver, A. J., and E. S. Sarachik, Evidence for decadal variability in an ocean general circulation model-An advective mechanism, Atmos. Ocean, 29(2), 197-231, 1991.

Weaver, A. J., J. Marotzke, P. F. Cummins, and E. S. Sarachik, Stability and variability of the thermohaline circulation, J. Phys. Oceanogr. 23(1), 39-60, 1993.

White, W. B., J. Lean, D. R. Cayan, and M. D. Dettinger, Response of global upper ocean temperature to changing solar irradiance, J. Geophys. Res., 102(C2), 3255-3266, 1997.

White, W. B., D. R. Cayan, and J. Lean, Global upper ocean heat storage response to radiative forcing from changing solar irradiance and increasing greenhouse gas/aerosol concentrations, J. Geophys. Res., 103(C10), 21,35521,366, 1998.

Winton, M., and E. S. Sarachik, Thermohaline oscillation induced by strong steady salinity forcing of ocean general circulation models, J. Phys. Oceanogr., 23, 1389-1410, 1993.

Wunsch, C., The interpretation of short climate records, with comments on the North Atlantic and Southern Oscillations, Bull. Am. Meteorol. Soc., 80(2), 245-255, 1999.

Yang, J., and J. D. Neelin, Decadal variability in coupled sea ice-thermohaline circulation systems, J. Clim., 10, 3059-3076, 1997.

G. Garric, CERFACS/MERCATOR-OCEAN, 8-10 rue Hermes, F-31520 Ramonville St Agne, France. (gilles.garric@mercator-ocean.fr) M. Huber, Earth and Atmospheric Sciences 1397 Civil Engineering Building, Purdue University, West Lafayette, IN 47907-1397, USA. (huberm@purdue.edu) 


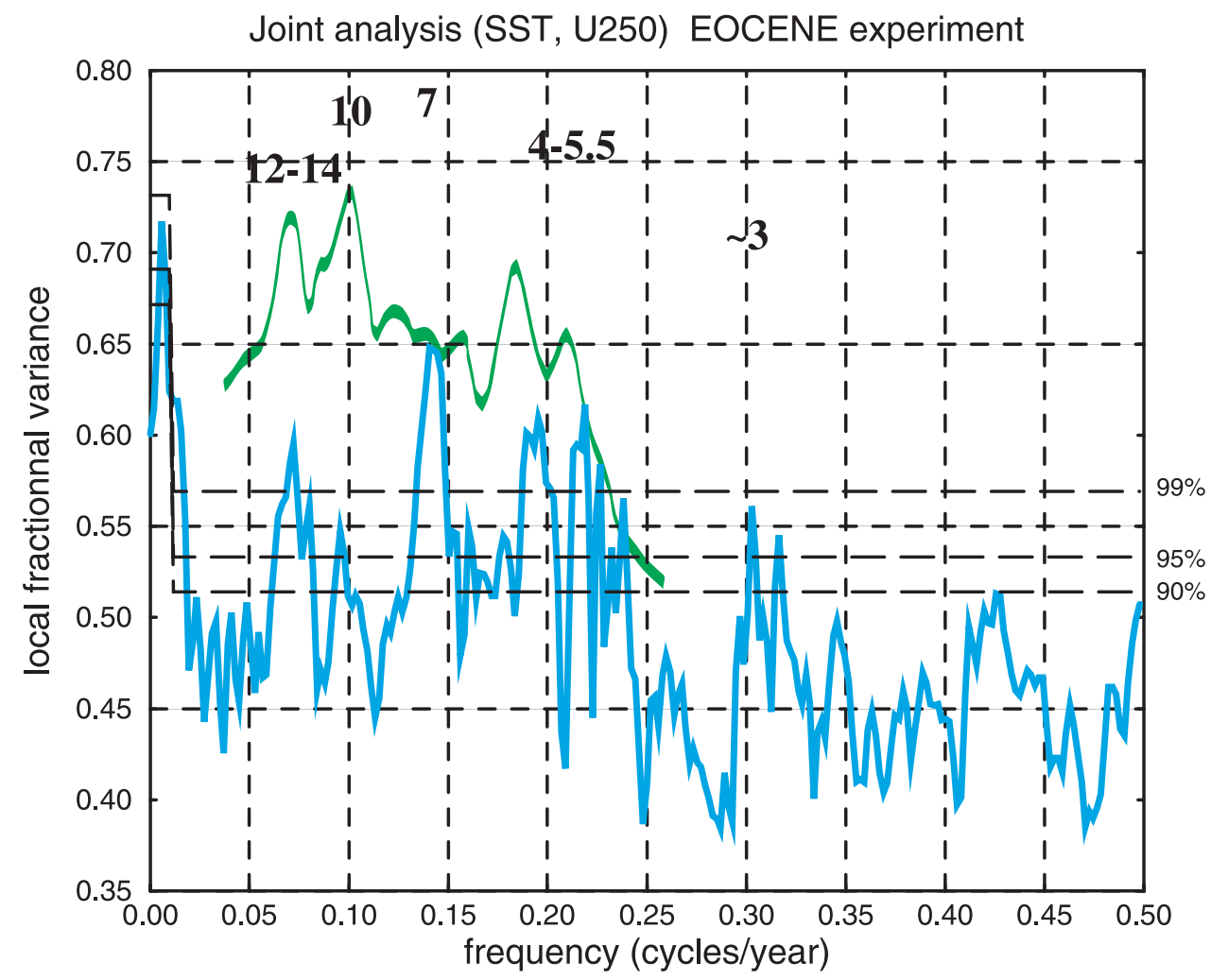

Figure 2. LFV spectrum of the joint zonal wind at $250 \mathrm{mb}$ and SST fields from Eocene CCSM simulation (blue). Significant peaks in the simulated spectra are indicated on figure. In green, is the stacked spectra from proto-Wyoming produced by Ripepe et al. [1991] reproduced here for comparison to the modeled spectra. Note that the confidence intervals apply only to the model LFV spectra (no estimates of statistical significance were made by Ripepe et al. [1991]). That spectra has been shifted up to make the detailed features more visible. 
phase 0 - year 0

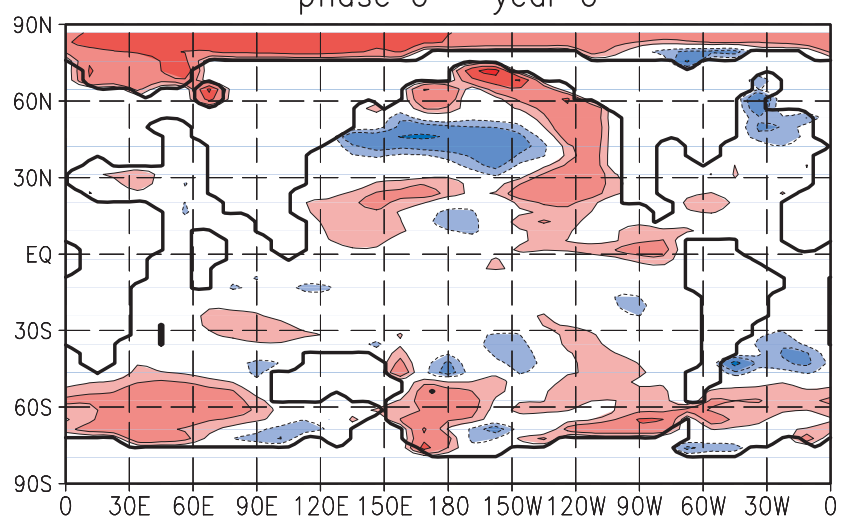

phase 60 - year 2

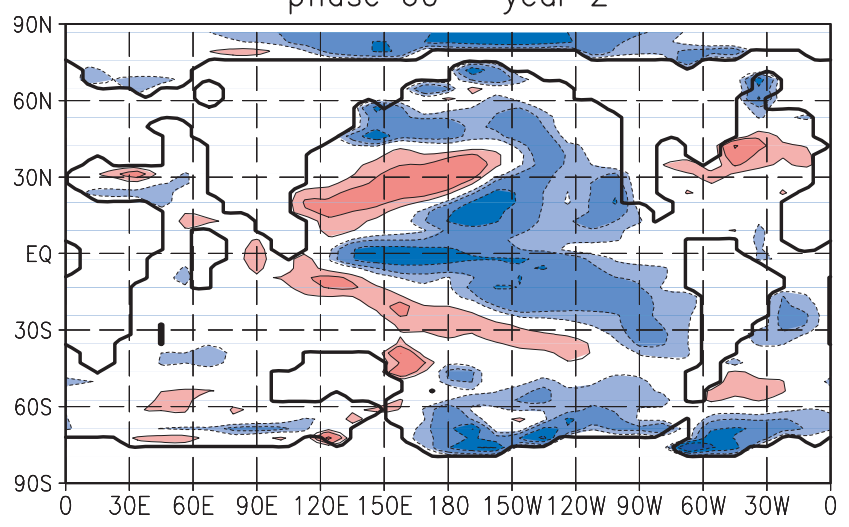

phase 120 - year 4

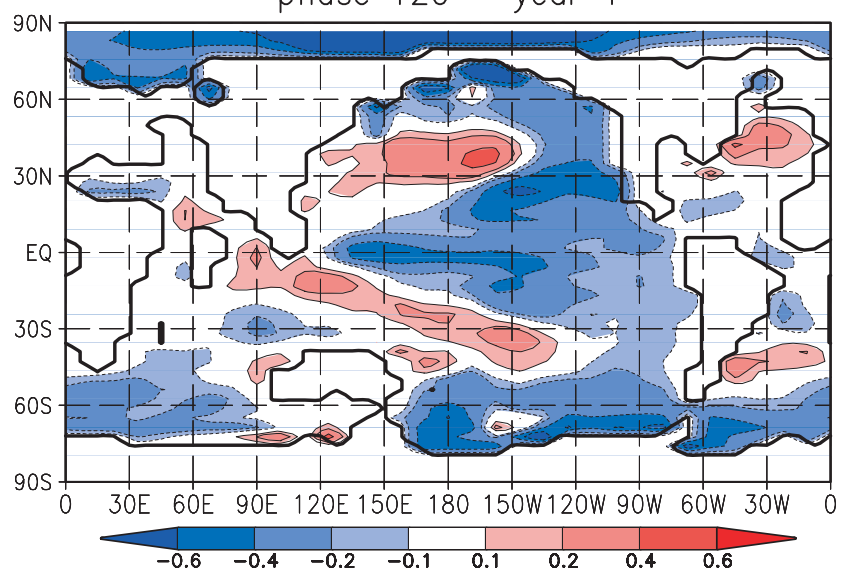

phase 180 - year 6

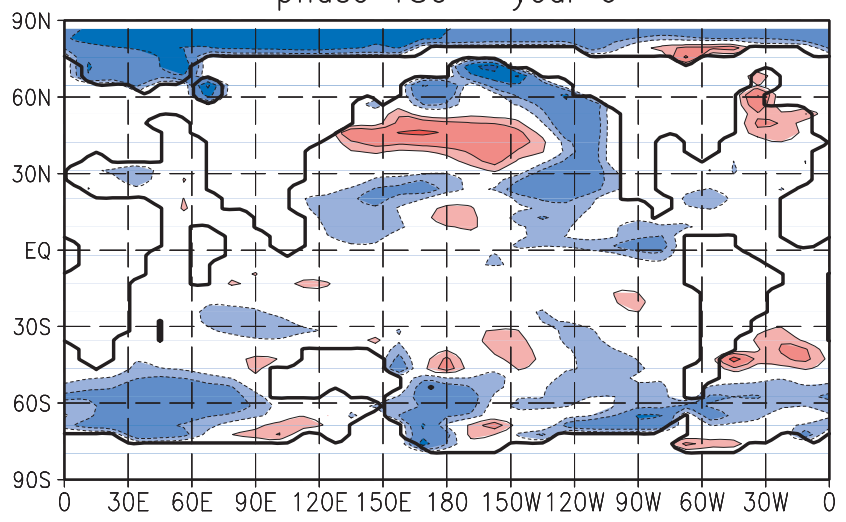

phase 240 - year 8

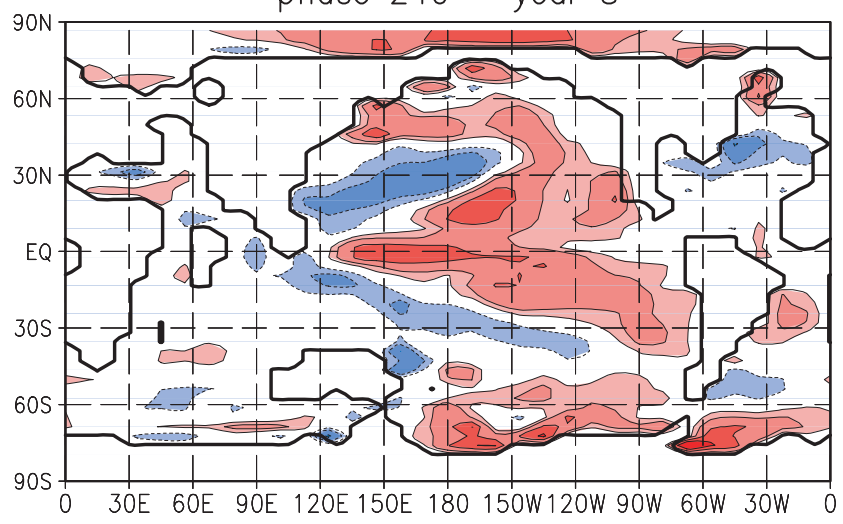

phase 300 - year 10

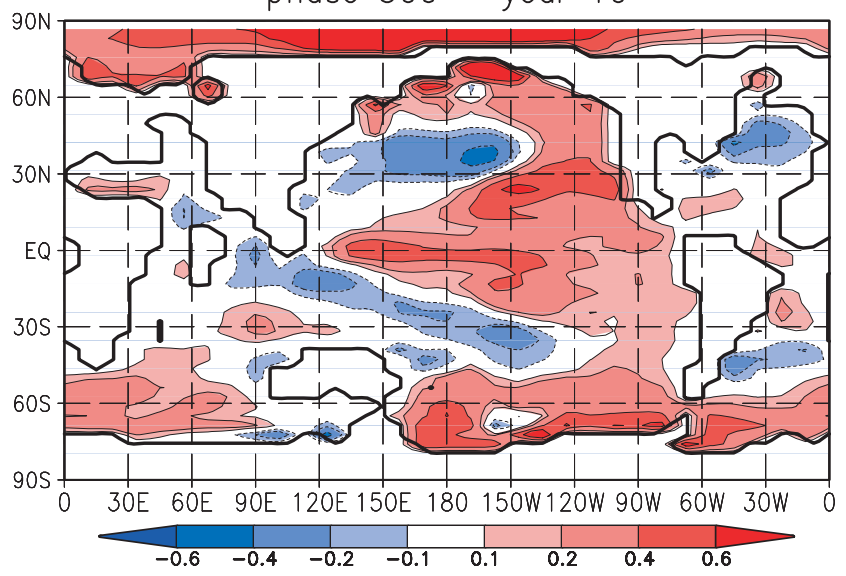

Figure 3. Spatial reconstruction of Eocene sea surface temperature anomalies (in ${ }^{\circ} \mathrm{C}$ ) during one complete QD cycle (12.5 years). The patterns are shown at 6 consecutive snapshots separated by approximately 2 years. 